\title{
UMA ANÁLISE DAS RESTRIÇÕES COMERCIAIS NO MERCADO INTERNACIONAL DE ALGODÃO
}

\author{
Marcela Olegário Santos ${ }^{1}$ \\ Orlando Monteiro da Silva ${ }^{2}$ \\ Fernanda Maria de Almeida ${ }^{3}$
}

Resumo: O principal consumo do algodão é para a fiação destinada a indústria têxtil. Por mais de 40 anos, a indústria têxtil e de vestuário foi regida pelo Acordo Multifibras, o qual não condizia com as regras impostas pelo GATT. Em 2005, tais medidas foram eliminadas e os produtos têxteis e de vestuários totalmente incluídos nessas regras. O objetivo deste estudo foi analisar o comércio internacional de algodão, com ênfase nas principais políticas comerciais adotadas e nos seus efeitos durante a transição e inserção do setor nas regras do GATT. Inicialmente, caracterizou-se o mercado internacional de algodão. Procedeu-se, então, com descrições e análises das principais políticas comerciais adotadas e, por fim, avaliaram-se os efeitos dessas políticas, sobretudo das medidas tarifárias e não tarifárias, sobre os fluxos bilaterais de comércio de algodão. Baseado no modelo gravitacional foi estimada uma regressão por PPML. Os resultados apontaram que as medidas técnicas contribuíram para o aumento da transparência permitindo avanços no comércio. No entanto, as tarifas são ainda prejudiciais aos países mais pobres. Assim, torna-se necessário implementar políticas comerciais que reduzam as barreiras para que os países menos desenvolvidos possam competir de forma justa e continuar ganhando participação no mercado internacional de algodão.

Palavras-chave: Algodão, modelo gravitacional, medidas técnicas e sanitárias.

\section{AN ANALYSIS OF TRADE RESTRICTIONS ON THE INTERNATIONAL COTTON MARKET}

Abstract: The main consumption of cotton is for spinning for the textile industry. For more than 40 years, the textile and clothing industry was governed by special discriminatory measures, which did not comply with GATT rules. In 2005, these measures were eliminated and the textile and clothing products were fully included in these rules. The objective of this study was to analyze cotton international trade, with emphasis in main trade policies adopted and their effects on the cotton trade during the transition and insertion of this sector into GATT rules. Initially, the cotton international market was characterized. Then, descriptions and analysis of the main commercial measures adopted in this market were also made; and, finally, the effects of the trade policies were evaluated, especially of the tariffs and non-tariffs measures, on the cotton trade flow among main trading partners. Based on the gravity model, a regression by

\footnotetext{
${ }^{1}$ Possui mestrado em Economia (2017) e graduação em Ciências Econômicas (2014) pela Universidade Federal de Viçosa.

2 Possui graduação em Agronomia (1976) e mestrado em Economia Rural (1979) pela Universidade Federal de Viçosa. É PhD em Economia pela North Carolina State University (1990), onde também fez um pós-doutorado (1997). Tem especialização em Integração Econômica pelo El Colégio de México, 1995.

${ }^{3}$ Possui graduação em Ciências Econômicas pela Universidade Federal de Viçosa (2007), Mestrado (2009) e Doutorado (2012) em Economia Aplicada também pela Universidade Federal de Viçosa.
}

Revista de Estudos Sociais | Ano 2017, N. 38, V. 19, Pag. 67 
PPML was estimated. The results indicated that the non-tariffs measures contributed positively to international cotton trade. However, tariffs were detrimental to the poorest countries. Thus, it's necessary to implement trade policies that reduce barriers so that the least developed countries can compete fairly and to continue gain market share in cotton international market.

Key words: Cotton, gravity model, technical and sanitary measures.

JEL: F13, F14, Q17

\section{Introdução}

A cadeia de produção do algodão para abastecer os setores têxteis e de vestuário é uma das mais longas e complexas quando comparada a outras cadeias agrícolas. Em virtude disso, o mercado mundial de algodão sempre foi fortemente regulado, principalmente porque o setor é grande absorvedor de mão de obra e muitos países buscam proteger o emprego doméstico impondo restrições ao livre comércio (BUAINAIN et al., 2007).

De fato, por mais de 40 anos, o comércio internacional de produtos têxteis e vestuário foi regido por medidas discriminatórias especiais, as quais não condiziam com as regras impostas pelo Acordo Geral sobre Tarifas Aduaneiras e Comércio (GATT) ${ }^{4}$. Um dos principais marcos regulatórios desse mercado foi - Acordo Multifibras (Multi-fibre Arrangement - MFA). O MFA convalidou 0 protecionismo determinado em acordos anteriores ${ }^{5}$, com a utilização de cotas de importação e, expandiu sua cobertura, que além de abranger produtos de algodão, passou a incluir praticamente todos os produtos, englobando as fibras sintéticas e as de lã (UNCTAD, 2008). O MFA permaneceu ativo até que os Acordos da Organização Mundial do Comércio (OMC) entraram em vigor em $1^{\circ}$ de janeiro de 1995.

Em 1994, durante a Rodada do Uruguai, foi criada a OMC, cujo objetivo é regulamentar o comércio internacional, fornecendo uma estrutura para negociação e administrando acordos comerciais, de forma a reduzir a utilização de políticas restritivas para que os fluxos comerciais internacionais ocorram de forma harmoniosa, justa, livre e previsível. Com a criação da OMC, foi estabelecido o Acordo sobre Têxteis e Vestuário (Agreement on Textiles and Clothing - ATC), que substituiu o MFA. O ATC prometia incluir os produtos têxteis e de vestuário nas normas do GATT, até 2004, e eliminar todas as cotas ainda existentes e estabelecidas pelo MFA. Esse acordo tem sido considerado uma das maiores conquistas resultantes das negociações da Rodada do Uruguai, visto que foi um importante passo na direção ao fortalecimento do sistema multilateral de comércio e para a integração desse mercado.

Desde então, as medidas regulatórias, medidas tarifárias e não tarifárias, têm sido alvo de grandes discussões para a formulação de políticas comerciais. As medidas não tarifárias mais utilizadas desde a criação da OMC, em 1995, são as medidas técnicas, representadas pelas notificações aos Acordos sobre

\footnotetext{
${ }^{4}$ O GATT foi adotado com o objetivo de reduzir as barreiras do comércio internacional por meio da redução de tarifas, quotas e subsídios (UNCTAD, 2008).

${ }^{5}$ Inicialmente, o comércio de produtos têxteis e de vestuário era governado pelo chamado Acordo Algodoeiro de Curto Prazo (Short-Term Cotton Arrangement), o qual se tornou Acordo de Longo Prazo (Long-Term Arrangement) e, mais tarde, o Acordo Multifibras (Multi-fibre Arrangement - MFA).
}

Revista de Estudos Sociais | Ano 2017, N. 38, V. 19, Pag. 68 
Medidas Sanitárias e Fitossanitárias (SPS) e sobre Medidas Técnicas (TBT). Esses acordos tem o objetivo de regulamentar o comércio internacional de forma a proteger o meio ambiente e a saúde humana, vegetal e animal contra riscos associados a produtos estrangeiros.

Questões relativas a políticas de restrições comerciais impostas ao comércio internacional vêm suscitando debates entre os países membros da OMC. Em 2015, os países membros da OMC concluíram a X Conferência Ministerial da OMC em Nairobi, Quênia, garantindo um acordo histórico sobre uma série de iniciativas comerciais relacionadas à agricultura e, principalmente, em relação ao algodão, devido à importância vital desse produto para os países menos desenvolvidos (WTO NEWS), 2016)

Apesar dos esforços da OMC para reduzir a utilização de políticas restritivas, líderes de países africanos têm questionado a falta de compromisso dos membros da $\mathrm{OMC}$ em cumprir o que foi estabelecido naquela conferência. Ainda há o receio de que as cotas de importação possam vir a ser substituídas, nos países desenvolvidos, por outras medidas não tarifárias que continuem restringindo o comércio.

Diante desse contexto e da grande relevância que o algodão tem para a economia mundial, principalmente, para muitos países pouco desenvolvidos e em desenvolvimento, o presente trabalho buscou identificar e analisar os efeitos das medidas tarifárias e técnicas (não tarifárias), sobre o mercado internacional de algodão.

Ao gerar informações sobre os efeitos dessas políticas comerciais sobre o comércio internacional de algodão, procura-se auxiliar os países inseridos nesse mercado na formulação de políticas comerciais e de estratégias de mercado que permitam gerar ganhos multilaterais de comércio.

Além dessa introdução, faz-se, na seção dois, uma descrição dos maiores países produtores e participantes do mercado internacional, descrevendo as principais políticas comerciais adotadas. A seção três descreve a metodologia utilizada para a análise, enquanto a seção quatro apresenta os resultados. A quinta e última seção apresenta um resumo e as conclusões da análise.

\section{O comércio e as políticas no mercado de algodão}

Com a utilização da biotecnologia na produção de algodão e a expansão de áreas cultivadas na África, Austrália, Brasil, China e Turquia, a partir de 1996, a produção mundial cresceu muito, ultrapassando 26 milhões de toneladas em 2004/05 e mantendo-se nesse patamar até a safra de 2014/15, exceto nas safras de 2008/09, 2009/10 e 2015/16 (ICAC, 2016a). Condições econômicas adversas contribuíram para a redução da produção nesses anos, entre elas a crise internacional, a competição pela cultura de outros produtos agrícolas, alterações climáticas (que afetaram o abastecimento de água para a irrigação) e a crescente aceitação de fibras sintéticas e artificiais pelos consumidores no mundo.

De acordo com dados do International Cotton Advisory Committee (ICAC, 2016), no período de 1995/96 a 2015/16, os principais produtores de algodão foram China, Índia, Estados Unidos, Paquistão e Brasil. Atualmente, esses países são responsáveis por mais de $75 \%$ da produção mundial. A produção dos EUA registrou tendência positiva entre as safras de 1998/99 até 2005/06, mas

Revista de Estudos Sociais | Ano 2017, N. 38, V. 19, Pag. 69 
após esse período, sua produção entrou em declínio. Em contrapartida, observou-se aumento na produção de países em desenvolvimento a partir de 2003/04, principalmente, da Índia e do Brasil.

Por vários séculos a fibra de algodão foi o principal insumo para a indústria têxtil, mas perdeu importância no mercado para as fibras sintéticas. Enquanto em 1995/96, a fibra de algodão correspondia a aproximadamente $47 \%$ do consumo global de fibras, em $2013 / 14$ essa participação foi reduzida para $32 \%$ (Figura 1).
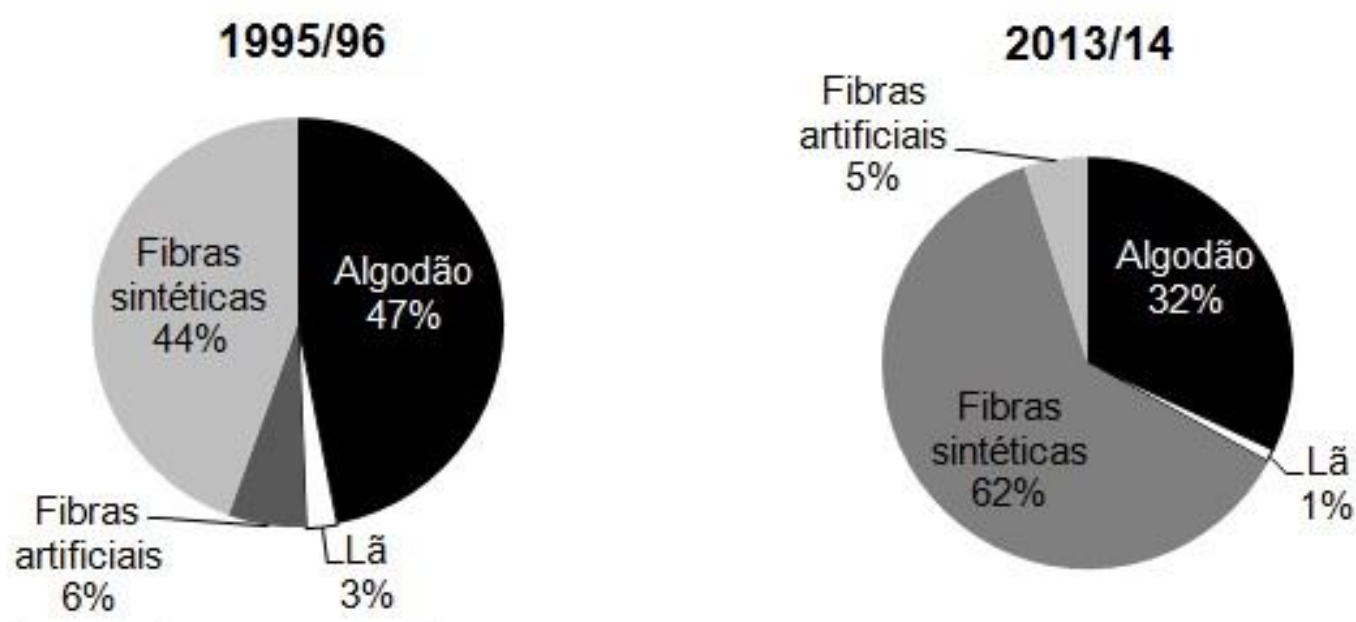

Figura 1: Composição do consumo Mundial de fibras. Safras 1995/96 e 2013/14. Fonte: Adaptado de Shui e Plastina (2013) e ICAC (2013).

Junto ao forte crescimento econômico, a partir da década de 90, os países asiáticos tiveram aumento progressivo da capacidade instalada e expansão do setor têxtil e de vestuário, apresentando grande destaque nesse cenário. Atualmente, China, Índia e Paquistão são os maiores consumidores de algodão, responsáveis por $62 \%$ do consumo mundial de fibras de algodão, seguidos pela Turquia, Estados Unidos e Brasil.

Uma alta volatilidade dos preços do algodão gerou, contudo, grandes variações no consumo internacional. Desde 1995/96 tem ocorrido oscilações no consumo e na produção de algodão, mas, foi no período entre 2010/11 a 2014/15, que tais oscilações foram mais acentuadas. Essa oscilação fez com que a diferença entre produção e consumo, como visualizado na Figura 2, permanecesse por um período maior, com uma acumulação de estoque que chegou a 13,6 milhões de toneladas de algodão (ICAC, 2016). De acordo com Cotlook (2016), esse acúmulo de estoque gerou uma tendência negativa sobre os preços do algodão no período subsequente. Somente com a redução gradativa dos estoques, a partir de março de 2016, é que essa tendência foi revertida. 


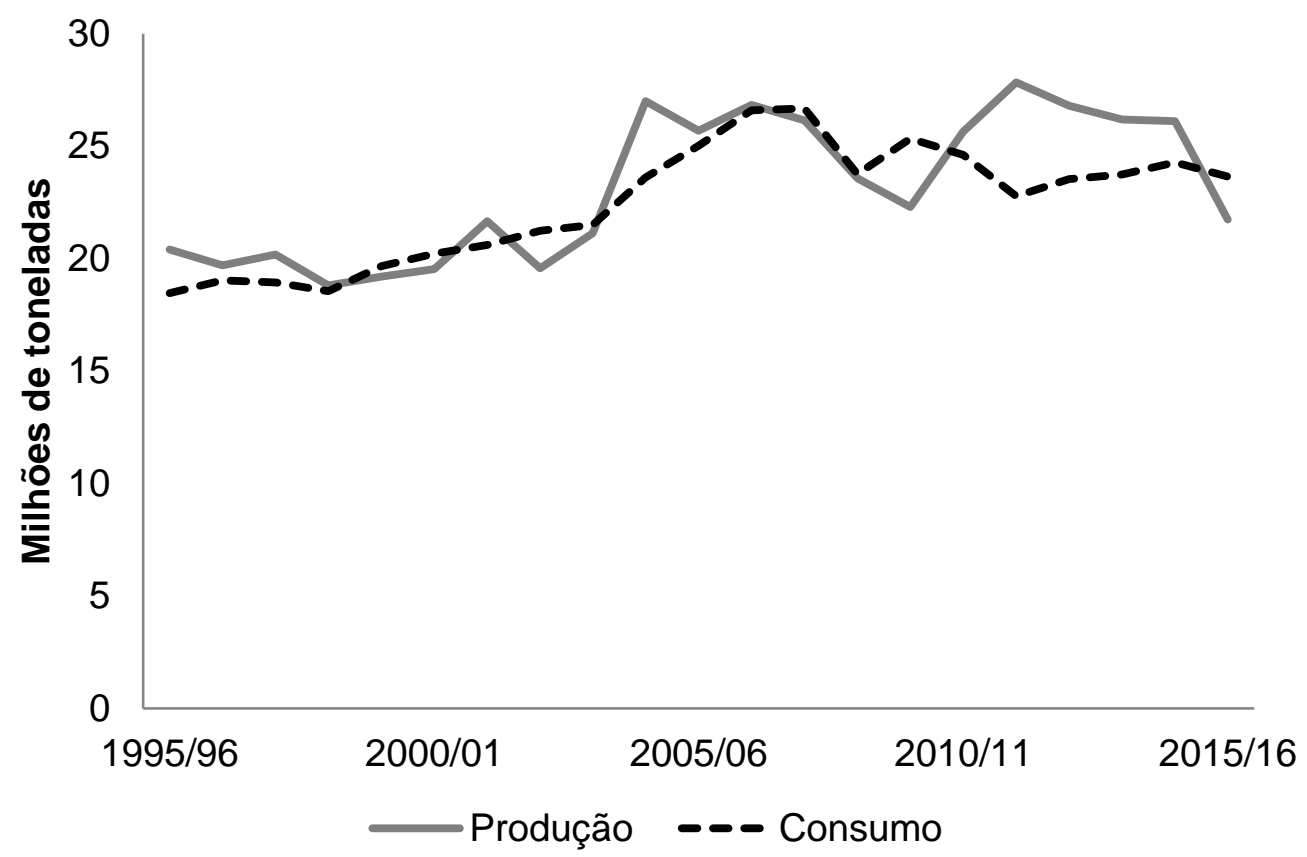

Figura 2: Produção e consumo mundiais. Safras 1995/96 a 2015/16. Fonte: ICAC, 2016.

O cultivo de algodão está presente em cerca de 100 países, mas a produção para o mercado externo é concentrada, tradicionalmente, em poucos deles. No período de 1995/96 a 2015/16, a quantidade de algodão comercializada no mercado internacional cresceu, em média, aproximadamente $43 \%$ (ICAC, 2016). Com a inclusão total do setor têxtil e de vestuário nas regras do GATT e a eliminação do sistema de cotas, em 2004, houve um aumento de $30 \%$ na quantidade de algodão comercializada. Em 2004/05, foram comercializados aproximadamente 7,3 milhões de toneladas de algodão, já em $2005 / 06$, esse valor foi de cerca 9,6 milhões de toneladas. Por outro lado, a crise econômica de 2008 afetou drasticamente o comércio internacional de algodão, registrando uma contração aproximada de $22 \%$. Também, entre as safras de 2012/13 e 2014/15, foi registrada uma redução do comércio por consequência do acúmulo de estoque no período entre 2010/11 e 2014/15 (ICAC, 2016).

Os dados do IGAC (2016) mostram que os principais exportadores de algodão são os Estados Unidos, Índia e Brasil, seguidos por Uzbequistão, Austrália, Burkina Faso e Mali. Nesse cenário vale ressaltar a perda de participação das exportações dos EUA no comércio internacional de algodão, que em 2005/06 correspondia a 39\% do total exportado. Em 2015/16, a participação norte-americana caiu para $27 \%$, voltando ao percentual aproximado ao da safra 1995/96. Em contrapartida, países em desenvolvimento, principalmente, Brasil, Índia e países da África Francófona ${ }^{6}$ registraram ganhos significativos na participação das exportações totais.

Sob a ótica das importações tem-se que os principais destinos do algodão são os países asiáticos. Atualmente, os principais países importadores são Bangladesh, China, Indonésia, Paquistão, Tailândia, Turquia e Vietnã. Vale

\footnotetext{
${ }^{6}$ Benin, Burkina Faso, Costa do Marfim, Guiné, Mali, Níger, Senegal, Togo, Camarões, República CentroAfricana, República do Congo, Gabão, Guiné Equatorial, Chade, Comores, Madagáscar, Ilha da Reunião. Revista de Estudos Sociais | Ano 2017, N. 38, V. 19, Pag. 71
} 
chamar a atenção para o fato de que em 1995/96, esses países eram responsáveis por apenas $30 \%$ das importações totais e, atualmente, tem participação de aproximadamente $75 \%$ das importações totais (ICAC, 2016). Certamente, esse aumento expressivo nas importações foi impulsionado pela expansão da capacidade produtiva do setor têxtil e de vestuário desses países durante a década de 90.

De acordo com Nassar (2007), geralmente, o algodão é comercializado internacionalmente em fardos. Uma vez colhida, a fibra é separada da semente (processo de descaroçamento) antes de ser vendida para fiação. A fibra de algodão é classificada de acordo com a qualidade da fibra, que é medida pelo comprimento de grampo, pela força, pela cor e pela uniformidade. Essas características podem variar dependendo dos fornecedores e do ano agrícola, no entanto, a variedade de sementes e a tecnologia utilizada para o descaroçamento são os principais determinantes dessas características.

Ao analisar os dados fornecidos por UNCOMTRADE (2016), no período de 1996 a 2015, o algodão, não cortado e nem penteado (HS520100) foi responsável, em média, por $95 \%$ do comércio total, sendo os outros $5 \%$ distribuídos entre os produtos resíduos de fios de algodão (HS520210), fiapos de algodão (HS520291), resíduos de fios de algodão, exceto os fiapos (HS520299) e algodão, cortado e penteado (HS520300).

As políticas comerciais impostas pelos países interferem diretamente no comportamento da produção, dos preços e, consequentemente, dos fluxos comerciais. Geralmente, tais políticas são implementadas por meio de medidas regulatórias sob a forma de tarifas e de medidas não tarifárias, as quais, em sua maioria, tendem a proteger os mercados internos e restringir o comércio. No caso do mercado internacional de algodão, destacam-se os subsídios, as tarifas e as medidas técnicas, referentes às exigências técnicas, sanitárias e fitossanitárias.

Em relação às tarifas, dados do UNCTAD Trade Analysis Information System (WITS, 2016) revelam que as tarifas médias efetivamente aplicadas pelos países em desenvolvimento no comércio internacional de algodão são muito superiores às aplicadas pelos países desenvolvidos. As maiores tarifas médias registradas nesse comércio são impostas pelos países asiáticos. Destacam-se nesse cenário a China, com uma tarifa média de aproximadamente $19,68 \%$, seguida pela Índia, Paquistão e Uzbequistão, com tarifas de 16,15\%, $13,51 \%$ e $11,07 \%$, respectivamente.

O algodão não cortado nem penteado registrou a maior tarifa média entre os filamentos de algodão (5,19\%), enquanto a média dos demais produtos desse segmento girou em torno de aproximadamente $2 \%$. Além disso, esse produto apresentou, junto ao algodão cortado e penteado, a maior variância, com tarifas oscilando de $0 \%$ a $90 \%$. Certamente, isso está estritamente relacionado à participação desse produto no comércio de filamentos de algodão, responsável por, em média, 95\% desse comércio no período entre 1996 e 2015 (WITS, 2016).

No período de 1995 a 2015, o comércio internacional de algodão registrou a emissão de 52 notificações. Desse total, 18 trataram do acordo TBT e 34, do SPS, das quais todas foram regulares, não havendo nenhuma notificação emergencial expedida. A Figura 3 mostra a evolução do total de notificações dos 
acordos de medidas técnicas (TBT) e sanitárias e fitossanitárias (SPS) emitidas entre os anos de 1995 e 2015, destinadas ao mercado internacional de algodão.

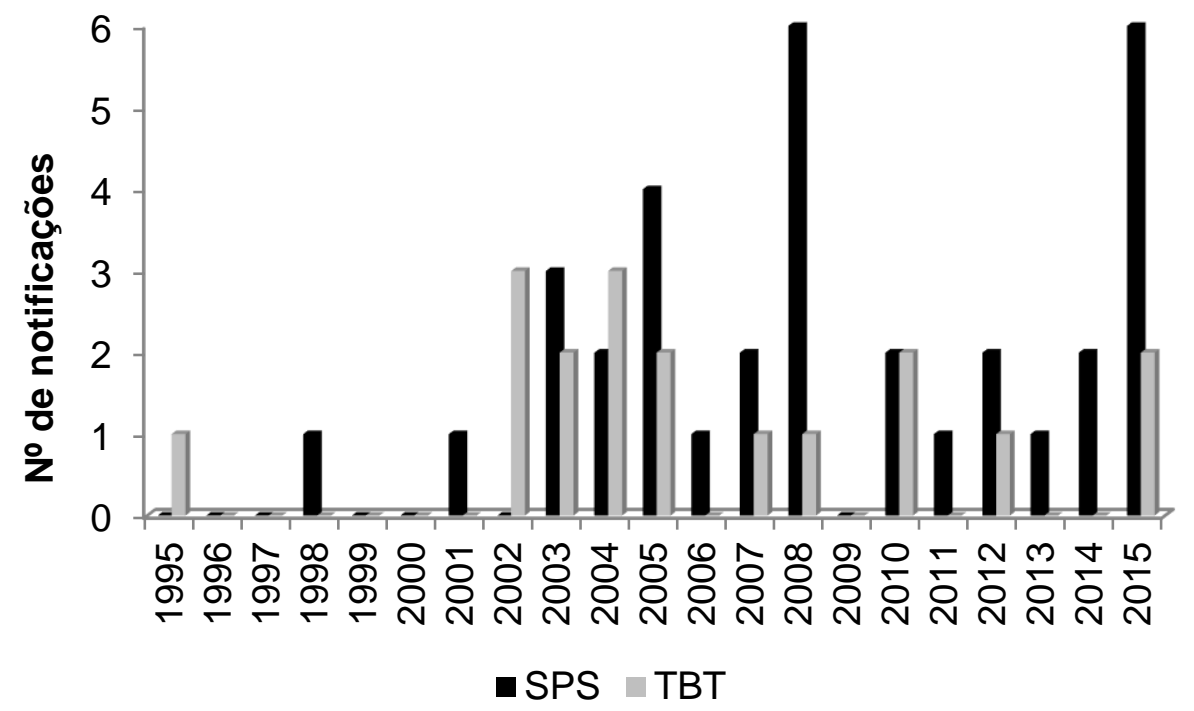

Figura 3: Evolução do total de notificações emitidas, dos acordos SPS e TBT, destinadas ao mercado internacional de algodão (1995-2015).

Fonte: World Trade Organization (WTO), 2016.

Observou-se o aumento das emissões de notificações em três períodos. O primeiro deles, entre 2002 e 2005, durante a transição para a liberalização do comércio internacional de algodão. Posteriormente, em 2008, durante a crise internacional e, por fim, em 2015, devido à redução do estoque acumulado entre as safras 2010/11 e 2014/15 e consequente aumento no volume de comércio. Certamente, o comportamento das notificações emitidas está relacionado a esses acontecimentos, sem que haja como precisar o impacto e a importância relativa de cada um deles.

Entre os principais países do comércio internacional de algodão, apenas Brasil e China emitiram notificações, em sua maioria referente ao acordo TBT, com objetivos relacionados à rotulagem, proteção à saúde humana e ao consumidor, que permitem o aumento de informações aos consumidores. Provavelmente, a emissão de notificações pela China é consequência da sua grande participação no consumo e nas importações de algodão durante o período entre 1996 e 2015. Já no Brasil foi devido a sua inserção no mercado internacional de algodão e pelo ganho considerável na participação nas exportações mundiais ao longo desse período. Por essas razões, China e Brasil tendem a adequar e padronizar suas práticas com aquelas adotadas no comércio internacional pelos seus parceiros.

Além das políticas mencionadas, os governos costumam adotar medidas de apoio interno para o setor de algodão de forma a garantir a renda dos cotonicultores. Os subsídios para o setor de algodão incluem apoio direto a produção, mecanismos de garantia de preços mínimos, subsídios de seguro de colheita e proteção das fronteiras, os quais, frequentemente, ditam 0 comportamento dos preços e dos fluxos comerciais.

No período entre as safras de 1997/98 e 2007/08, 55\% da produção mundial de algodão, em média, recebeu subsídios diretos dos governos, 
incluindo transferências diretas e proteção de fronteira. Essa estimativa aumentou para $83 \%$ em 2008/09 e recuou no período seguinte, entre 2009/10 e 2013/14, para 48\%. Em 2014/15 e 2015/16, a proporção da produção mundial de algodão a receber assistência dos governos correspondeu a 73,5\% em média (ICAC, 2016a). No entanto, de acordo com ICAC (2016a), estima-se que a assistência direta a produção de algodão em 2016 seja de US $\$ 7,2$ bilhões, valor $30 \%$ menor do que o recorde registrado em 2014/15, quando atingiu US\$10,7 bilhões.

Nos últimos 18 anos, os países que deram mais assistência à produção de algodão foram China e Estados Unidos, seguidos por Grécia, Turquia e Espanha. Em sua maioria, regiões em desenvolvimento, tais como Brasil, Mali, Burkina Faso, Paquistão e Índia, alocaram menos recursos para subsidiar a produção de algodão.

\section{As barreiras ao comércio internacional}

A tarifa é a forma mais simples de política comercial, pois consiste em um imposto cobrado sobre o preço do produto importado. Esse imposto pode ser cobrado tanto na forma de um valor fixo por unidade do produto, chamado de tarifa específica, como também na forma de uma taxa ad valorem, quando é cobrada uma percentagem sobre o valor do produto importado. Há ainda tarifas mistas, quando se cobra uma tarifa específica sobre o preço de uma determinada quantidade do produto e uma tarifa ad valorem sobre o excesso daquela quantidade (KRUGMAN; OBSTFELD, 2005).

A Figura 4 ilustra o efeito da imposição de uma tarifa no mercado doméstico em relação ao algodão vindo do mercado estrangeiro. Na ausência de custos de transporte e da tarifa $(\mathrm{t})$, o preço do algodão $(\mathrm{Pw})$ seria igual tanto no mercado doméstico como no mercado estrangeiro. Uma vez implementada a tarifa no país importador, ocorreria aumento do preço doméstico, passando de $\mathrm{P}_{w}$ para $\mathrm{P}_{t}$, e redução do preço estrangeiro, passando de $\mathrm{P}_{\mathrm{w}}$ para $\mathrm{P}_{t}{ }^{*}$, fazendo com que a diferença seja igual ao valor da tarifa t. Assim, com a tarifa há uma perda social referente a área $A+B+C+D$, que pode ser observada pela redução das quantidades ofertadas e demandadas no mercado mundial de algodão.

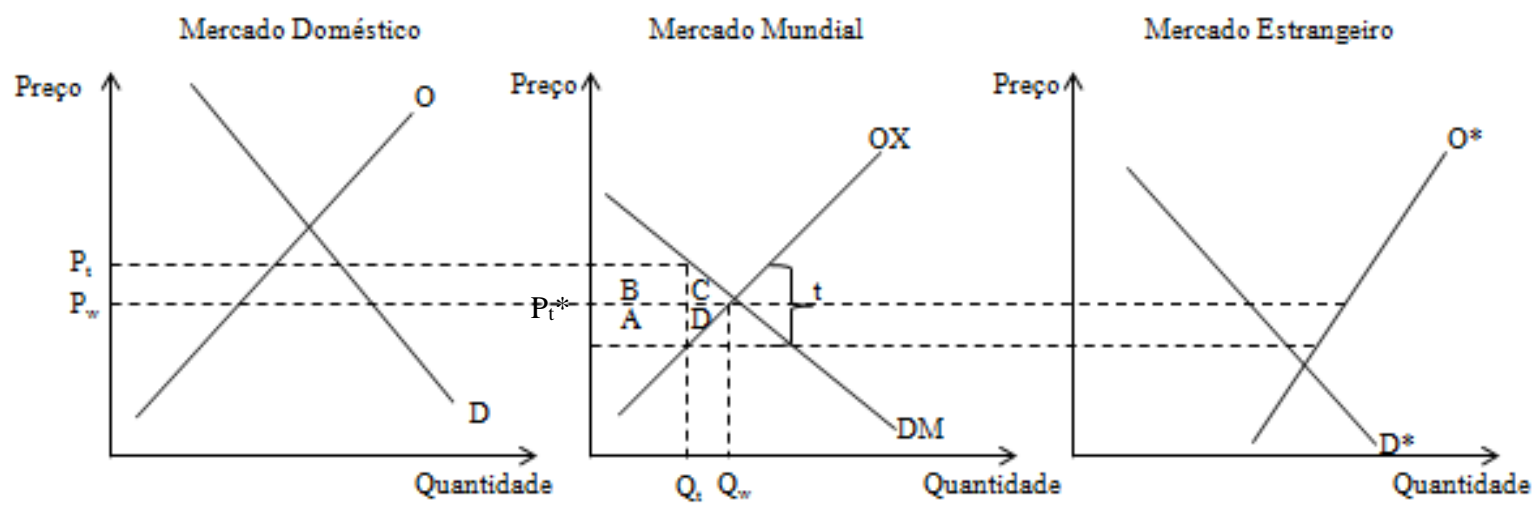

Figura 4: Efeitos da aplicação de uma tarifa sobre um produto importado. Fonte: KRUGMAN \& OBSTFELD (2005).

Com a criação da OMC, as tarifas têm perdido força e, em alguns mercados, sido substituídas, gradativamente, por barreiras não tarifárias. De

Revista de Estudos Sociais | Ano 2017, N. 38, V. 19, Pag. 74 
acordo com Hillman (1991), as barreiras não tarifárias (BNTs) podem ser definidas como "todas as restrições ou práticas governamentais, diferentes dos impostos alfandegários habituais, que impedem a entrada de importações em um país". Exemplos de medidas não tarifárias, que podem atuar como barreiras ao comércio, são as cotas de importação, restrições voluntárias a exportações e exigências técnicas, sanitárias e fitossanitárias. No entanto, nem sempre estas medidas técnicas atuam no mercado de forma a restringir o comércio.

Não é possível determinar de forma exata o efeito da imposição de medidas técnicas sobre o comércio. No entanto, deve-se considerar que, de alguma maneira, essa imposição altera tanto a posição quanto a inclinação da curva de demanda de algodão. A partir de estudos precedentes ${ }^{7}$, Roberts, Josling e Orden (1999) propuseram uma análise diferenciada dos efeitos das medidas regulatórias sobre o comércio internacional. Aqueles autores analisam situações diferentes sobre a imposição destas medidas por meio de três componentes: da proteção regulatória, do deslocamento da oferta (supply-shift) e do deslocamento da demanda (demand-shift).

O componente de proteção regulatória sugere que as medidas regulatórias fornecem benefícios aos produtores domésticos. Nesse cenário, 0 cumprimento desses regulamentos age no comércio internacional como a imposição de uma tarifa. Como resultado, os produtores nacionais ganham e os consumidores perdem, pagando tanto pelo ganho do produtor como pelo custo da regulamentação.

O segundo componente, deslocamento da oferta, evidencia os reflexos das importações sobre o mercado doméstico. Nesse caso, a Figura 5 esboça, por exemplo, os efeitos da imposição de uma medida SPS por um mercado importador (país pequeno) no comércio mundial de algodão. No mercado importador, So e $P_{0}$ são, respectivamente, a oferta e o preço doméstico na ausência de comércio internacional. Quando o país importador se abre ao comércio internacional, há uma mudança na inclinação da curva de oferta para $\mathrm{S}_{1} \mathrm{e}$, consequentemente, um aumento da demanda no mercado mundial, de forma que as importações aumentam de $M_{1}$ para $M_{2}$, com o novo preço $P_{1}$.
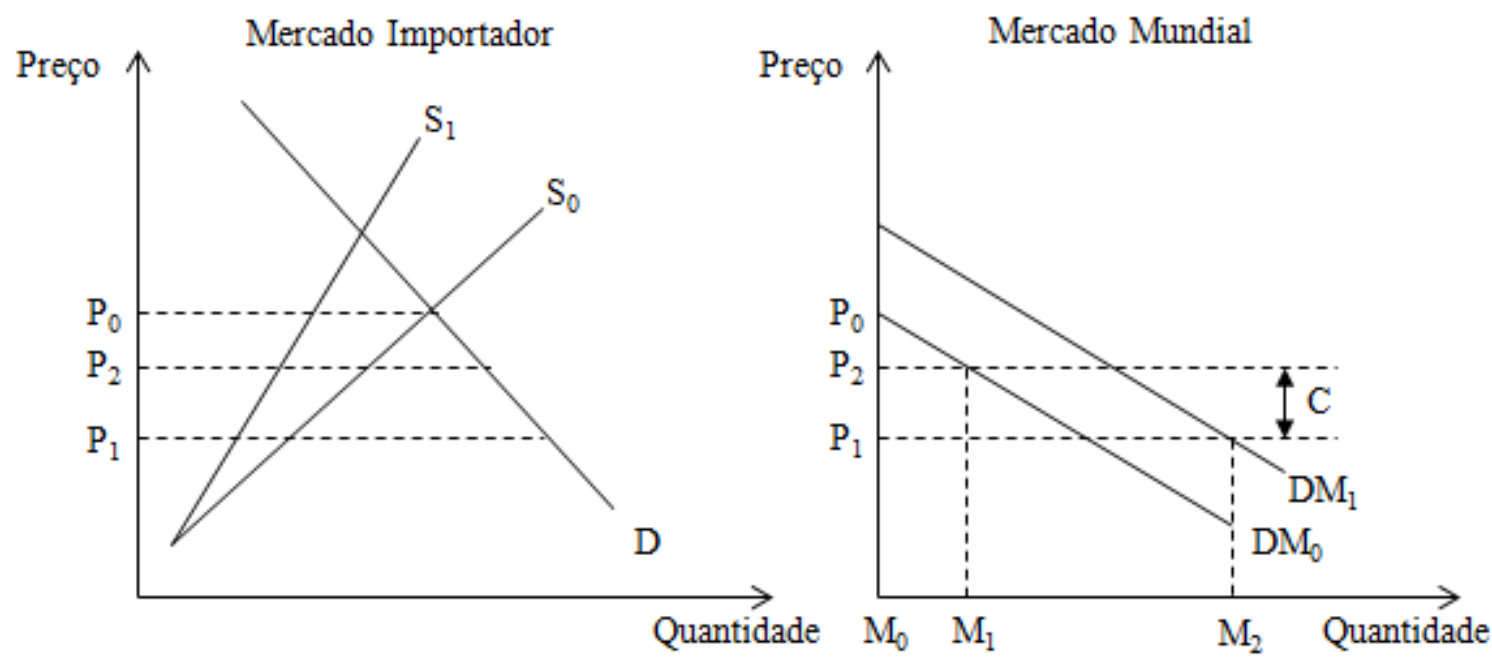

\footnotetext{
${ }^{7}$ Orden e Romano(1996); Krissoff, Calvin e Gray (1997); Sumner e Lee (1997); Thilmany e Barret (1997); e, Paarlberg e Lee (1998).
}

Revista de Estudos Sociais | Ano 2017, N. 38, V. 19, Pag. 75 
Figura 5: Efeitos da imposição de medidas regulatórios, deslocamento da oferta.

Fonte: Adaptado de Roberts, Josling e Orden (1999).

Caso a entrada de produtos estrangeiros tenha causado algum prejuízo ao mercado doméstico, por exemplo, em consequência de uma externalidade negativa ligada ao aparecimento de uma doença ou peste, o governo do país importador impõe uma medida SPS, que implica no aumento do preço de importação para $\mathrm{P}_{2}$. Esse aumento seria devido ao custo de adaptação dos países exportadores às novas exigências do país importador. Dessa forma, até que seja sanado o problema, a demanda mundial retorna a $\mathrm{DMo}$, porém a um preço mais elevado $\left(\mathrm{P}_{2}\right)$.

Já o componente de deslocamento da demanda destaca a imposição de uma medida regulatória contendo informações adicionais que permitam aos consumidores aumentar significativamente a demanda. Como apresentado na Figura 6, a imposição de uma medida técnica pelo governo devido à exigência de um regulamento contendo informações esclarecedoras aos consumidores provoca uma mudança na inclinação da demanda interna do país importador, de $D_{0}$ para $D_{1}$, tornando-a mais elástica. Como a imposição dessa medida incorre em um custo, haverá um aumento de preços de $P_{0}$ para $P_{1}$. No entanto, mesmo com um preço mais alto, a quantidade importada aumenta, devido à mudança de inclinação da curva de demanda interna, resultando em um deslocamento da curva de demanda mundial, de $\mathrm{DM}_{0}$ para $\mathrm{DM}_{1}$, e um ganho de comércio referente às áreas $A+B$.
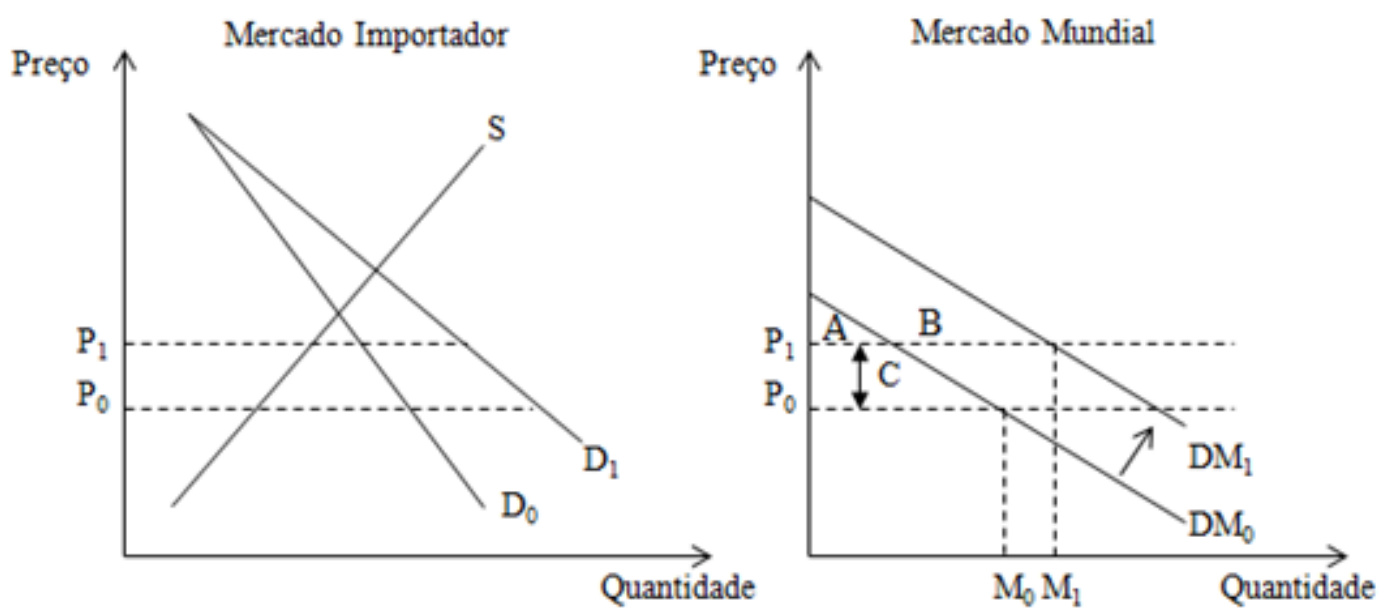

Figura 6: Efeitos da imposição de medidas regulatórios, deslocamento da demanda.

Fonte: Adaptado Roberts, Josling e Orden (1999).

\section{Metodologia}

O modelo proposto para a análise dos efeitos das restrições comerciais ao mercado internacional de algodão é o modelo de gravidade. Desde sua introdução na economia, por Tinbergen (1962), o modelo de gravidade tem sido amplamente utilizado para explicar os fluxos de comércio bilaterais e tornou-se uma das principais ferramentas de trabalho de economistas ligados à economia

Revista de Estudos Sociais | Ano 2017, N. 38, V. 19, Pag. 76 
internacional (CHENG; WALL, 2005; HELBLE; SHEPHERD; WILSON, 2007). Até a década de 70, a lei da gravidade de Newton era aplicada aos modelos econômicos apenas intuitivamente, relacionando os fluxos de comércio bilaterais com o PIB e com as medidas de resistência comercial, representadas pela distância entre eles.

O uso dessa metodologia para a análise de políticas econômicas passou a ser questionada nas décadas de 70 e 80, devido à inexistência de um embasamento teórico que sustentasse a relação empírica idealizada por Tinbergen. No fim da década de 70, Anderson (1979) estabeleceu as bases estruturais para um modelo de gravidade econômica estática e, em 2003, Anderson e van Wincoop (2003) derivaram o modelo que se adapta às mais variadas teorias do comércio internacional. Assumindo que os consumidores têm preferência por variedade, tal modelo considera um sistema de demanda para o qual se propõe uma função de elasticidade de substituição constante - CES (Constant Elasticity of Substitution) - para os consumidores do país importador, sujeita a uma restrição orçamentária, que produz uma equação não linear com o termo de erro multiplicativo, com a seguinte forma estrutural:

$$
X_{i j}^{k}=\frac{Y_{i}^{k} E_{j}^{k}}{Y^{k}}\left(\frac{\mathrm{T}_{\mathrm{ij}}^{\mathrm{k}}}{\Pi_{i}^{k} P_{j}^{k}}\right)^{1-\sigma_{k}} e_{i j}^{k}
$$

em que, $X_{i j}^{k}$ corresponde as exportações do país $i$ para o país $j$ do produto $k ; Y$ é o Produto Interno Bruto (PIB); E é a despesa, a qual não é necessariamente igual ao PIB; $Y^{k}=\sum_{i=1}^{c} Y_{i}^{k}$ é o PIB mundial; $\sigma_{k}$ é a elasticidade de substituição intrassetorial; $\mathrm{t}_{i j}^{k}$ são os custos de comércio; $\Pi_{i}$ e $P_{j}$ são índices de resistência multilateral ao comércio; e, $e_{i j}^{k}$ é o termo de erro aleatório.

A principal característica do modelo proposto por Anderson e van Wincoop (2003) é a inclusão dos índices de resistência multilateral ao comércio, variáveis não observáveis que são incluídas ao modelo utilizando efeitos fixos. Esse modelo ratifica o fato de que mudanças nos custos de comércio bilateral podem afetar todos os fluxos comerciais por causa dos efeitos dos preços relativos.

As contribuições de Anderson e van Wincoop (2003) configuraram-se em uma base teórica importante para a consolidação dos modelos da gravidade e permitiram o avanço de outros trabalhos, tais como os de Chaney (2008), Helpman et al. (2008) e Olivero e Yotov (2012).

Dada a descrição anterior sobre o mercado internacional de algodão, o presente trabalho buscou analisar os efeitos das tarifas e das medidas não tarifárias (técnicas, sanitárias e fitossanitárias) sobre comércio bilateral do produto entre os principais países exportadores e importadores desse mercado no período de 1996 a 2015. Inicialmente, foi feito um levantamento e identificação das medidas regulatórias utilizadas que, juntamente com as variáveis básicas do modelo de gravidade, foram utilizadas para estimação do modelo econométrico.

Assim, de acordo com o modelo teórico proposto, a especificação funcional log-linear para a equação de gravidade estimada pode ser expressa por:

$$
\begin{gathered}
\ln X_{i j t}^{k}=\mathrm{c}+\alpha_{\mathrm{it}}+\delta_{\mathrm{jt}}+\beta_{1} \ln \mathrm{Y}_{\mathrm{it}}+\beta_{2} \ln \mathrm{Y}_{\mathrm{jt}}+\beta_{3} \ln \mathrm{D}_{\mathrm{ij}}+\beta_{4}\left(1+t_{j i t}^{k}\right)+\beta_{5} \mathrm{TBT}_{\mathrm{jit}}+ \\
\beta_{6} \mathrm{SPS}_{\mathrm{jit}}+\beta_{7} \mathrm{D}_{1}+\beta_{8} \mathrm{D}_{2}+\ln \varepsilon_{i j}
\end{gathered}
$$

Revista de Estudos Sociais | Ano 2017, N. 38, V. 19, Pag. 77 
em que $X_{i j t}^{k}$ corresponde aos valores dos fluxos de comércio internacional bilateral nominal do exportador $i$ para o importador $j$ do produto $k$ no ano $t ; \mathrm{c}$, constante; $\alpha_{i t}$ e $\delta_{j t}$ representam os efeitos fixos para o país exportador $i$ e importador j; Y $_{\mathrm{it}}$ e $Y_{\mathrm{jt}}$ são, respectivamente, o PIB dos países exportador $i$ e importador $j$, no tempo $t$; $\mathrm{D}_{\mathrm{ij}}$ representa a distância bilateral, em $\mathrm{km}$, da capital do país $i$ à capital do país $j$; $t_{j i t}$ é a tarifa imposta às importações de cada um dos produtos do país i pelo país $j$, no ano t; TBT jit, variável dummy que recebe valor 1 caso o país $j$ tenha emitido notificações do acordo TBT para os produtos de algodão do país ino ano t; SPS jit, variável dummy que recebe valor 1 caso o país j tenha emitido notificações do acordo SPS para os produtos de algodão do país $i$ no ano t; $D_{1}$ é uma variável dummy, representando os anos posteriores à eliminação total do sistemas de cotas do mercado de algodão (2005 a 2015); $D_{2}$ é uma variável dummy, representando as exportações dos países em desenvolvimento e menos desenvolvidos após a eliminação total do sistemas de cotas do mercado de algodão (2005 a 2015) e, $\varepsilon_{i j t}$ é o termo de erro.

Para estimação, foram utilizados dados em painel desagregados por produto de acordo com o Sistema Harmonizado de seis dígitos (HS-06) no período de 1996 a 2015. Assim, a análise deste estudo envolveu um painel com o comércio bilateral entre 14 países no período de 1996 a 2015, gerando um banco de dados de 1.960 observações de fluxos bilaterais de comércio (98 pares de países x 20 anos). Além disso, utilizaram-se variáveis dummies para países exportadores e importadores, mas, devido à falta de relevância para as conclusões, estas variáveis não foram apresentadas, sendo necessárias apenas para evitar que seus efeitos afetem os coeficientes das demais variáveis.

Essa regressão foi estimada baseada no comércio bilateral entre os principais países exportadores: Austrália, Brasil, Burkina Faso, Estados Unidos, Índia, Mali e Uzbequistão; e importadores do comércio internacional de algodão: Bangladesh, China, Indonésia, Paquistão, Tailândia, Turquia e Vietnã; por meio dos métodos MQO, com os dados pooled e, com efeitos fixos, por MQO e PPML. Para isso utilizou-se os dados de comércio do produto algodão, não cortado nem penteado (HS520100), principal produto comercializado no mercado internacional de filamentos de algodão.

Optou-se pela utilização do método PPML para a interpretação dos coeficientes estimados pelo fato dos resultados gerados, por meio desse método, serem consistentes na presença de efeitos fixos e de heteroscedasticidade e, além disso, por permitir a presença de fluxos de comércio iguais à zero ou missing na base de dados. Os modelos pooled e MQO com efeitos fixos foram estimados para uma análise comparativa entre os modelos e, assim, ressaltar a importância da inserção dos índices de resistências multilaterais e dos fluxos de comércio iguais à zero para a robustez do modelo.

A especificação do modelo foi aferida utilizando o teste de Ramsey Regression Equation Specification Error Test (RESET). O teste RESET detecta se variáveis potenciais foram omitidas na especificação do modelo. A hipótese nula afirma que o modelo não possui erros de especificação, sugerindo que 0 modelo está bem especificado, sendo rejeitada quando o $p$-valor for menor que o valor crítico.

\footnotetext{
${ }^{8}$ Os efeitos fixos tanto para os exportadores quanto para os importadores absorvem todas as características observáveis e não observáveis que influenciam os fluxos bilaterais de comércio. Revista de Estudos Sociais | Ano 2017, N. 38, V. 19, Pag. 78
} 
Os dados utilizados na estimação das equações são secundários e anuais, cuja descrição e fontes encontram-se na Tabela 1.

Tabela 1: Descrição e fonte das variáveis utilizadas

\begin{tabular}{|c|c|c|}
\hline Variável & Descrição & Fonte \\
\hline$X^{k}{ }_{i j t}$ & $\begin{array}{c}\text { Valor FOB das importações do produto } k \text { de cada um dos } \\
\text { países importadores para os respectivos exportadores, em } \\
\text { dólares. }\end{array}$ & $\begin{array}{l}\text { WITS (2016) - } \\
\text { UNCOMTRADE }\end{array}$ \\
\hline$Y_{i t} \in Y_{j t}$ & $\begin{array}{l}\text { PIB nominal dos países exportadores e importadores, } \\
\text { respectivamente, em dólares. }\end{array}$ & $\begin{array}{l}\text { WORLD BANK } \\
\qquad(2016)\end{array}$ \\
\hline$D_{i j}$ & $\begin{array}{c}\text { Distância bilateral, em km, da capital do país } i \text { à capital do } \\
\text { país } j \text {. }\end{array}$ & CEPII(2016) \\
\hline$t^{k}{ }_{j i t}$ & Tarifa imposta pelo país $j$ ao produto $k$ do país $i$ no ano $t$. & $\begin{array}{l}\text { WITS }(2016)- \\
\text { TRAINS }\end{array}$ \\
\hline $\mathrm{TBT}_{\mathrm{jit}}$ & $\begin{array}{l}\text { Variável dummy que recebe valor } 1 \text { caso o país } j \text { tenha } \\
\text { emitido notificações do acordo TBT para os produtos de } \\
\text { algodão do país } i \text { no ano } t \text {. }\end{array}$ & $\begin{array}{l}\text { WTO (2016) - World } \\
\text { Trade Indicators }\end{array}$ \\
\hline $\mathrm{SPS}_{\mathrm{jit}}$ & $\begin{array}{l}\text { Variável dummy que recebe valor } 1 \text { caso o país } j \text { tenha } \\
\text { emitido notificações do acordo SPS para os produtos de } \\
\text { algodão do país } i \text { no ano } t \text {. }\end{array}$ & $\begin{array}{l}\text { WTO }(2016) \text { - World } \\
\text { Trade Indicators }\end{array}$ \\
\hline$D_{1}$ & $\begin{array}{c}\text { Variável dummy, representando os anos posteriores à } \\
\text { eliminação total do sistemas de cotas do mercado de } \\
\text { algodão (2005 a 2015). }\end{array}$ & - \\
\hline $\mathrm{D}_{2}$ & $\begin{array}{c}\text { Variável dummy, representando as exportações dos países } \\
\text { em desenvolvimento e menos desenvolvidos após a } \\
\text { eliminação total do sistemas de cotas do mercado de } \\
\text { algodão (2005 a 2015). }\end{array}$ & - \\
\hline
\end{tabular}

Fonte: Elaboração própria.

\section{Resultados}

$\mathrm{Na}$ Tabela 2 estão apresentados os resultados obtidos para os coeficientes do produto algodão não cortado e nem penteado (HS520100), pelos métodos pooled e com efeitos fixos por MQO e PPML. Inicialmente, ao comparar os resultados gerados pelos métodos pooled e MQO com efeitos fixos, a primeira característica notável é o poder explicativo dos modelos. Observou-se, por meio do $\mathrm{R}^{2}$, que o poder explicativo deste último método $(64,82 \%)$ é muito superior ao pooled (16,56\%), demonstrando a importância da inclusão das variáveis não observáveis das resistências multilaterais na explicação dos fluxos de comércio.

O segundo ponto a ser observado é a grande diferença nos coeficientes sob as duas especificações. Geralmente, nos mercados de bens, observam-se elasticidades-distância próximas a -1 (SHEPHERD, 2013). A diferença encontrada entre as elasticidades deixa claro que a estratégia na escolha do método a ser utilizado pode fazer uma diferença expressiva sobre o resultado final.

Ainda que os resultados obtidos sejam satisfatórios, o método MQO com efeitos fixos não é o mais adequado por não resolver o problema da heteroscedastidade dos dados e não permitir a inclusão de fluxos comerciais

Revista de Estudos Sociais | Ano 2017, N. 38, V. 19, Pag. 79 
nulos ou missing no banco de dados. É por essa razão, que o método PPML tem um número superior de observações (1.960) comparado ao daquele (894). Sendo assim, a ênfase na análise foi dada aos resultados estimados pelo método PPML com efeitos fixos. Foi observado que o modelo estimado por PPML ajustou-se aos dados relativamente bem, com $R^{2}$ igual a 0,7310 , indicando que as variáveis explicativas foram responsáveis por aproximadamente $73 \%$ das variações observadas nos dados do comércio bilateral do algodão, não cortado nem penteado.

$\mathrm{Na}$ análise dos coeficientes, a variável distância apresentou coeficiente estimado negativo e estatisticamente significativo a $1 \%$, indicando que, na média, um aumento de $1 \%$ na distância entre os países tende a reduzir 0 comércio em $0,959 \%$. Isso corrobora o fato de que quanto maior à distância, maiores são os entraves para se efetivar as transações comerciais, devido, principalmente, aos custos de transporte, considerados como um dos maiores custos logísticos no comércio e que possuem grande influência sobre o preço final do produto.

Tabela 2: Resultados obtidos dos coeficientes estimados para o produto algodão, não cortado nem penteado, por pooled e, com efeitos fixos, por MQO e PPML

\begin{tabular}{|c|c|c|c|}
\hline & Pooled & $\begin{array}{c}\text { Efeitos fixos } \\
\text { (MQO) }\end{array}$ & $\begin{array}{c}\text { Efeitos fixos } \\
\text { (PPML) }\end{array}$ \\
\hline $\operatorname{lnPib}_{\text {it }}$ & $\begin{array}{c}0,338^{\star \star *} \\
(0,029)\end{array}$ & - & - \\
\hline $\operatorname{lnPib} b_{j t}$ & $\begin{array}{c}-0,074^{\mathrm{NS}} \\
(0,112)\end{array}$ & - & - \\
\hline InDistância ${ }_{i j}$ & $\begin{array}{c}0,419^{* * *} \\
(0,114)\end{array}$ & $\begin{array}{c}-1,024^{* * *} \\
(0,207)\end{array}$ & $\begin{array}{c}-0,959^{\star * *} \\
(0,127)\end{array}$ \\
\hline Tarifa $_{i j t}$ & $\begin{array}{l}1,997^{* *} \\
(0,901)\end{array}$ & $\begin{array}{c}-1,616^{\star *} \\
(0,674)\end{array}$ & $\begin{array}{c}-1,336^{\star \star *} \\
(0,368)\end{array}$ \\
\hline SPS & $\begin{array}{l}1,412^{\mathrm{NS}} \\
(1,066)\end{array}$ & $\begin{array}{l}0,425^{\mathrm{NS}} \\
(0,617)\end{array}$ & $\begin{array}{l}0,333^{*} \\
(0,192)\end{array}$ \\
\hline TBT & $\begin{array}{c}1,261^{\star * *} \\
(0,458)\end{array}$ & $\begin{array}{l}0,404^{\text {NS }} \\
(0,275)\end{array}$ & $\begin{array}{c}0,557^{\star * *} \\
(0,148)\end{array}$ \\
\hline$D_{1}$ & $\begin{array}{c}-0,522^{N S} \\
(0,349)\end{array}$ & $\begin{array}{l}0,358^{*} \\
(0,199)\end{array}$ & $\begin{array}{c}0,930^{* * *} \\
(0,137)\end{array}$ \\
\hline $\mathrm{D}_{2}$ & $\begin{array}{c}2,280^{* * *} \\
(0,297)\end{array}$ & $\begin{array}{c}1,277^{\star \star *} \\
(0,262) \\
\end{array}$ & $\begin{array}{c}1,195^{\star * *} \\
(0,240)\end{array}$ \\
\hline Observações & 894 & 894 & 1960 \\
\hline Obs. excluídas & - & - & 0 \\
\hline$R^{2}$ & 0,1656 & 0,6482 & 0,7310 \\
\hline $\begin{array}{l}\text { Teste Reset } \\
p \text {-valores }\end{array}$ & 0,0000 & 0,0000 & 0,3250 \\
\hline
\end{tabular}

Revista de Estudos Sociais | Ano 2017, N. 38, V. 19, Pag. 80 
Fonte: Elaboração própria.

Os valores entre parênteses referem-se aos erros-padrão robustos estimados.

* Nível de significância de 10\%.

** Nível de significância de 5\%.

*** Nível de significância de $1 \%$.

NS Não significativo estatisticamente.

Assim como a distância, a variável tarifa também apresentou coeficiente estimado negativo e estatisticamente significativo a 1\%. Vale chamar a atenção sobre a alta elasticidade dessa variável, a qual indica que uma variação nas tarifas desse produto provoca uma mudança mais que proporcional sobre o valor comercializado, de forma que, na média, uma redução de $10 \%$ no valor das tarifas aumentaria o comércio de algodão em 12,75\%.

Esse resultado é preocupante, visto que a redução tarifária tornaria esse mercado mais competitivo e consequentemente, permitiria que os países em desenvolvimento e os menos desenvolvidos tivessem maiores ganhos no comércio, contribuindo, assim, para o crescimento e desenvolvimento dessas regiões.

Além de identificada a alta elasticidade da tarifa sobre o comércio do algodão não cortado nem penteado observou-se que esse produto registrou as maiores tarifas média e máxima no mercado internacional de algodão. Essas constatações têm consequências relevantes sobre o mercado internacional de algodão devido à participação expressiva desse produto no comércio de algodão, ratificando a necessidade de rever as tarifas aplicadas.

Como observado anteriormente, as medidas tarifárias foram amplamente utilizadas no comércio internacional de algodão, no período analisado, por todos os países em análise. Embora sua trajetória tenha sido descendente nos últimos anos, as tarifas ainda causam efeitos negativos e significativos sobre o mercado internacional de algodão. Nesse cenário, destacam-se os países asiáticos (China, Índia, Paquistão e Uzbequistão), que registraram as maiores médias tarifárias.

Apesar de não ter apresentado média tarifária elevada, os Estados Unidos registraram o maior número de picos tarifários junto àqueles países. Devido ao grande destaque dos Estados Unidos e dos países asiáticos, as políticas comerciais impostas por eles têm impactos significativos sobre todo o mercado.

Os efeitos dos regulamentos técnicos (TBT), sanitários e fitossanitários (SPS) sobre os fluxos bilaterais foram captados por meio das variáveis dummies na equação proposta ${ }^{9}$. De acordo com os resultados obtidos, os coeficientes das medidas técnicas (TBT) e sanitárias e fitossanitárias (SPS) foram positivos e estatisticamente significativos. Os resultados permitiram inferir que as notificações emitidas pelos acordos TBT e SPS aumentaram o comércio, respectivamente, em média, $74,5 \%$ e $39,5 \%$, o que indica que essas notificações não se configuraram como BNTs no período em análise.

De acordo com Thilmany e Barrett (1997), o efeito positivo sugere que apesar do aumento nos custos dos países exportadores para se adaptarem às exigências dos importadores, a adoção de regulamentos com conteúdo

\footnotetext{
9 O efeito de uma variável dummy sobre o volume comercializado pode ser calculado em termos percentuais da seguinte forma: $\left(e^{\widehat{\beta}_{\text {dummy }}}-1\right) \times 100$ (YOTOV et al., 2016).

Revista de Estudos Sociais | Ano 2017, N. 38, V. 19, Pag. 81
} 
informativo estimula a demanda e aumenta o comércio, gerando resultado líquido positivo.

Entre os países em análise, apenas Brasil e China emitiram notificações regulares impondo regulamentos técnicos, sanitários e fitossanitários sobre 0 comércio internacional de algodão. Entretanto, as emissões desses dois países corresponderam a aproximadamente $70 \%$ do total de notificações emitidas pelo acordo TBT direcionadas ao comércio de algodão.

Os resultados positivos obtidos já eram esperados, visto que grande parte dos objetivos descritos nas medidas técnicas impostas por esses países está relacionada à rotulagem, proteção à saúde humana e ao consumidor que permitem o aumento de informações aos consumidores gerando impacto positivo sobre o comércio mesmo com o aumento de custo.

Tendências recentes mostram que os países que iniciam negociações comerciais não buscam apenas maior acesso aos mercados, mas também a redução de incertezas. Lejárraga e Shepherd (2013) ressaltam a importância da transparência para o processo de liberalização do mercado, de forma que mercados com maior assimetria de informações têm maior probabilidade de permanecer fechados. Assim, os resultados confirmam que esses acordos têm contribuído com o compromisso de transparência no comércio internacional de algodão reforçando a aplicação de regras e reformas de abertura comercial.

Para captar o impacto da liberalização do comércio internacional de algodão foram utilizadas variáveis dummies, em que $\mathrm{D}_{1}$ assumiu valor unitário para os anos posteriores à eliminação total do sistema de cotas do mercado de algodão (2005 a 2015); e D2, para as exportações dos países em desenvolvimento e menos desenvolvidos no período de 2005 a 2015.

Apesar do comércio de algodão ter ficado mais suscetível às oscilações do mercado internacional com a liberalização, observou-se que a variável $D_{1}$ apresentou sinal positivo e estatisticamente significativo a $1 \%$, indicando que, no período entre 2005 a 2015, o comércio internacional de algodão aumentou, em média, $153,45 \%$. A variável $\mathrm{D}_{2}$ apresentou comportamento similar, apontando aumento de, em média, $230,35 \%$ nas exportações dos países em desenvolvimento e menos desenvolvidos após a eliminação total do sistema de cotas do mercado de algodão (2005 a 2015).

De fato esses resultados corroboram a análise desenvolvida por Nassar (2007), o qual ressaltou que antes do fim do ATC, as empresas desse setor já iniciaram novos investimentos com o intuito de estimular a demanda. A China, mesmo depois de alguns anos fora do mercado começou a importar grande volume de algodão a partir de 2002. Além da China, diversos países em desenvolvimento acompanharam essa tendência.

O autor também destaca o aumento na produção de algodão no Brasil e em países da África Subsaariana. Várias podem ter sido as causas do aumento das transações comerciais no mercado internacional de algodão após 2004, como observado na Figura 10, tais como abertura comercial dos países em desenvolvimento, ganhos de produtividade dos países exportadores, avanço tecnológico, entre outros.

Entretanto, o processo de liberalização do comércio internacional de algodão de 1995 a 2004, o consequente aumento da transparência e as contínuas negociações para a inclusão dos países em desenvolvimento foram,

Revista de Estudos Sociais | Ano 2017, N. 38, V. 19, Pag. 82 
sem dúvidas, decisivas para desencadear esses e outros fatores permitindo avanços nesse mercado.

\section{Conclusões}

O algodão tem grande relevância pela sua utilização na cadeia produtiva de diversos bens, contribuindo, efetivamente, para a geração de renda e emprego e, impulsionando o crescimento e desenvolvimento de países menos desenvolvidos. Contudo, é um mercado que ainda apresenta vários desafios a serem superados, principalmente, devido ao fato de ser fortemente regulado e condicionado a políticas comerciais, que, geralmente, restringem o livre fluxo de comércio.

Os resultados mostraram que, mesmo com a maior vulnerabilidade devido às oscilações no comércio de algodão com a liberalização, foi registrada uma taxa de crescimento maior do comércio após a eliminação das cotas de importação, principalmente, nos países menos desenvolvidos e em desenvolvimento, comparado ao período em que essas medidas não eram vigentes, reforçando os efeitos positivos da abertura comercial e da maior integração econômica.

Além disso, a inclusão de dispositivos de transparência por meio dos acordos TBT e SPS, apesar de elevar os custos, tem melhorado o acesso aos mercados e ampliado o comércio. Os mecanismos de transparência são a forma dos países mais desenvolvidos de garantir acesso efetivo ao mercado das economias emergentes, onde a falta de transparência e a corrupção podem constituir-se em barreiras. Outra consequência importante é que as normas de transparência dos acordos comerciais permitem alcançar um nível mínimo de convergência de práticas reguladoras, contribuindo para transmissão das melhores práticas em termos de transparência de forma a estimular o comércio.

Ainda que os resultados apontem maior transparência no comércio internacional de algodão, deve-se atentar às barreiras ainda presentes nesse mercado, tais como as tarifas e os subsídios e, além disso, acompanhar os efeitos das emissões de notificações dos acordos SPS e TBT, reforçando as discussões e negociações para reduzir as intervenções no mercado.

Grandes mudanças estão ocorrendo no cenário político internacional e incertos são seus efeitos sobre a economia internacional. Nessa nova conjuntura, para que não haja retrocessos, é de extrema importância sempre destacar os avanços obtidos na economia mundial devido à abertura comercial, a maior integração econômica e transparência dos mercados. Diante disso, discussões que avaliam e auxiliam na resolução de conflitos, gerados por decisões arbitrárias, são essenciais para obter resultados justos, equilibrados e que promovam ganho de bem-estar mundial.

\section{Referências bibliográficas}

ANDERSON, J. E. A theoretical foundation for the gravity equation. The American Economic Review, v. 69, n. 1, p. 106-116, 1979. Disponível em: 
<http://www.jstor.org/stable/1802501?seq=1\#page_scan_tab_contents $>$ Acesso em: mar/2016.

ANDERSON, J. E.; VAN WINCOOP, E.. Gravity with gravitas: a solution to the border puzzle. American Economic Review, v.93, n.1. 2003. Disponível em: <https://www.aeaweb.org/articles.php?doi=10.1257/000282803321455214> Acesso em: 15 janeiro 2016.

BUAINAIN, Antonio Márcio et al. (4 ${ }^{a}$ Ed.). Cadeia produtiva do algodão. Bib. Orton IICA/CATIE, 2007.

CHENG, I.; WALL, H. J. Controlling for heterogeneity in gravity models of trade and integration. Federal Reserve Bank of St. Louis Working Paper Series, Vol. 87, No. 1, pp. 49-63, 2005. Disponível em: <http://papers.ssrn.com/sol3/papers.cfm?abstract_id=656201> Acesso em: mar/2016.

CHANEY, Thomas. Distorted gravity: the intensive and extensive margins of international trade. The American Economic Review, v. 98, n. 4, p. 1707-1721, 2008.

COTLOOK (2016) - Cotton Outlook. < https://www.cotlook.com/>

HELBLE, M.; SHEPHERD, B.; WILSON, J. S.Transparency \& Trade Facilitation in the Asia Pacific: Estimating the Gains from Reform. Department of Foreign Affairs and Trade, 2007.

HELPMAN et al. Estimating trade flows: Trading partners and trading volumes. Quarterly Journal of Economics, 103(2): 441-487, 2008.

HILLMAN, J. S. Technical barriers to agricultural trade. Westview Press, 1991.

ICAC (2016) - International Cotton Advisory Committee - ICAC World Cotton

Database. Disponível em: < https://www.icac.org/ >

ICAC (2016a) - Production and trade policies affecting the cotton industry. Washington DC, USA: ICAC. October, 2016.

KRISSOFF, B.; CALVIN, L. Gray." Barrier to Trade in Global Apple Markets," Fruit and Tree Nuts Situation and Outlook/FTS-280/August. Economic Research Service, US Department of Agriculture, 1997.

KRUGMAN, P. R.; OBSTFELD, M. Economia internacional: teoria e política, 5a Ed. São Paulo: Markron Books, 2005.

LEJÁRRAGA, Iza; SHEPHERD, Ben. Quantitative evidence on transparency in regional trade agreements. OECD Trade Policy Papers, No. 153, OECD Publishing, Paris. 2013. http://dx.doi.org/10.1787/5k450q9v2mg5-en

NASSAR, André Meloni. Trade Liberalization in Cotton and Sugar. Agricultural Trade Liberalization and the Least Developed Countries, v. 19, p. 83, 2007.

OLIVERO, María Pía; YOTOV, Yoto V. Dynamic gravity: endogenous country size and asset accumulation. Canadian Journal of Economics/Revue canadienne d'économique, v. 45, n. 1, p. 64-92, 2012. 
ORDEN, David; ROMANO, Euardo. The avocado dispute and other technical barriers to agricultural trade under NAFTA. In: Paper present at the conference of NAFTA and Agriculture: Is the Experiment Working. 1996.

PAARLBERG, Philip L.; LEE, John G. Import restrictions in the presence of a health risk: an illustration using FMD. American Journal of Agricultural Economics, v. 80, n. 1, p. 175-183, 1998.

ROBERTS, Donna; JOSLING, Timothy E.; ORDEN, David. A framework for analyzing technical trade barriers in agricultural markets. Technical Bulletin, $n$. 1876, 1999.

SANTOS SILVA, JMC; TENREYRO, S. The log of gravity. The Review of Economics and statistics, v. 88, n. 4, p. 641-658, 2006. Disponível em: <http://www.mitpressjournals.org/doi/abs/10.1162/rest.88.4.641\#.VxeSSdQrLIU $>$ Acesso em: abr/2016

SHEPHERD, B. The gravity model of international trade: A user guide. ARTNeT Books and Research Reports, 2013. Disponível em: $<$ https://ideas.repec.org/b/unt/arbook/brr11.html> Acesso em: mai/2016

SUMNER, Daniel A.; LEE, Hyunok. Sanitary and phytosanitary trade barriers and empirical trade modeling. 1997.

THILMANY, D. D.; BARRETT, C. B. Regulatory barriers in an integrating world food market. Review of Agricultural Economics, p. 91-107, 1997

TINBERGEN, Jan. Shaping the world economy; suggestions for an international economic policy. Books (Jan Tinbergen), 1962.

UNCOMTRADE (2016) - United Nations Comtrade Database - International Trade Statistics. Disponível em:< https://comtrade.un.org/>.

UNCTAD - United Nations Conference on Trade and Development. Training module on trade in textiles and clothing the post-ATC context. UNCTAD/DITC/TNCD/2005/19. United Nations, New York and Geneva, 2008.

WITS - World Integrated Trade Solution. Database. Disponível em: <https://wits.worldbank.org/> Acesso em: abr/2016

WTO - World Trade Organization. Trade topics. Disponível em: $<$ https://www.wto.org/s. Acesso em 2016.

YOTOV, Yoto V. et al. An Advanced Guide to Trade Policy Analysis: The Structural Gravity Model. World Trade Organization, Geneva, 2016. 